\title{
PENGARUH STRATEGI PEMBELAJARAN TERHADAP KEMAMPUAN KOGNITIF DAN KREATIVITAS DALAM MENYELESAIKAN SOAL MATEMATIKA
}

\author{
Muh. Bachtiar Azis ${ }^{1}$
}

\begin{abstract}
The Influence of Learning Strategy Towards Cognitive Ability and Creativity in Solving Mathematics Problems (An Experiment Study on Students at SMPN in Bone District. The Study aims at examining the influence of learning strategy towards cognitive ability and students' creativity in solving Mathematics problems. The population of the study was the entire SMPN in Bone district with A accreditation and students of grade VII at SMPN 1 Watampone and SMPN 2 Watampone with as many as 129 students were chosen. The samples of the study were 25 grade VII.B students at SMPN 1 Watampone and 25 grad VII.A students at SMPN 2 Watampone.The Study was an experiment research with factorial desin. Data were collected using test result instrument in a form on an essay. Data were analyzed by employing desriptive analysis and inferential analysis with SPSS 22.00 program.The result of the study revealed that students' cognitive ability taught by employing mind map learning strategy at the experiment 1 was in high category. Students' cognitive ability taught by employing expository learning strategy at the experiment 2 was in fair category. Students' creativity in solving Mathematics problems taught by employing mind map learning strategy at the experiment 1 was in fair category on the aspects $f$ fluency, flexibility, and originality; whereas, students' creativity in solving Mathematics problems taught by employing expository learning strategy at experiment 2 was in fair category on the aspects of fluency, flexibility, and originality. The results indicated that there were differences between cognitive ability and creativity in solving Mathematics problems of students who were taught by employing mind map learning strategy and expository learning strategy.
\end{abstract}

Keywords: Cognitive Ability and Students Creativity

\section{PENDAHULUAN}

Pada pengajaran matematika guru lebih banyak menyampaikan sejumlah ide atau gagasan-gagasan matematika, sementara dalam pembelajaran matematika siswa mendapat porsi lebih banyak dari ada guru, bahkan mereka harus dominan dalam kegiatan belajar mengajar. Dalam kegiatan pembelajaran, siswa berperan aktif sebagai pembelajar dan fungsi guru lebih pada sebagai fasilitator. Kenyataan menunjukkan bahwa dalam pembelajaran matematika, strategi pembelajaran selama ini masih didominasi dengan strategi pembelajaran ekspositori. Hal ini diperkuat berdasarkan hasil observasi dan

\footnotetext{
${ }^{1}$ Manajemen Pendidikan Islam Institut Agama Islam Negeri (IAIN) Bone.
} 
wawancara terbatas yang penulis lakukan dengan guru matematika di beberapa SMP di SMP Negeri Kabupaten Bone yang terakreditasi A menunjukkan bahwa guru-guru perencanaan dan penerapan pembelajaran yang dilakukan masih dominan dengan metode transfer informasi, dan masih menggunakan strategi pembelajaran konvensional inilah adalah salah satu faktor penyebab rendahnya hasil belajar siswa. Kondisi pembelajaran seperti ini akanmenimbulkan kebosanan bagi siswa, siswa tidak dapat melihat hubungan antar materi pelajaran yang telah dipelajari dengan materi berikutnya. Ini diperparah dengan sikap guru yang tidak pernah mengingatkan kembali siswa tentang materi sebelumnya dan terus melanjutkan tanpa memperhatikan apakah siswa pada umumnya telah memahami materi yang diberikan sehingga pelajaran matematika tidak menarik, tidak disenangi, dan dengan sendirinya pelajaran matematika akan terasa sulit. Dengan demikian sebagai konsekuensinya hasil belajar yang di capai siswa di beberapa SMP di SMP Negeri Kabupaten Bone termasuk SMP Negeri 1 Watampone dan SMP Negeri 2 Watampone belum sesuai dengan harapan.

Dengan melihat kenyataan di lapangan, wawancara dengan guru matematika SMP Negeri 1 Watampone dan SMP Negeri 2 Watampone, untuk pencapaian hasil belajar yang optimal diperlukan strategi pembelajaran yang efektif mampu mengembangkan kemampuan kognitif dan kreativitas siswa. Salah satu alternatif pembelajaran yang dapat meningkatkan kemampuan kognitif dan kreativitas siswa adalah pembelajarn dengan Mind Map (peta pikir) agar dapat menghubungkan atau mengkaitkan antar konsep, sehingga terjadi kegiatan belajar bermakna. Mind map adalah metode mencatat kreatif yang memudahkan mengingat banyak informasi serta dapat meningkatkan kreativitas. Metode mencatat yang baik harus membantu dalam mengingat perkataan dan bacaan, serta meningkatkan pemahaman terhadap materi. Hal ini akan memungkinkan dengan peta pikiran yang dikembangkan oleh Buzan (2009). Setelah selesai membuat peta pikir, catatan tersebut akan membentuk suatu pola gagasan yang saling berkaitan dengan topik utama ditengah dan sub topik dan perincian menjadi cabang-cabangnya. Pola pencatatan peta pikir bertjuan membentuk skema (jejaring) informasi sehingga dapat mengkomodir bentuk keseluruhan dari suatu topic, kepentingan serta hubungan relatif antar masing-masing komponen dan mekanisme penghubungnya.

Bertitik tolak dari permasalahan, dan hal-hal yang telah dikemukakan diatas, maka penulis merasa terdorong untuk mengkajinya dalam bentuk penelitian eksperimen pada siswa SMP Negeri di SMP Negeri Kabupaten Bone yang terakreditasi A yaitu SMP Negeri 
1 Watampone dan SMP Negeri 2 Watampone. Dengan judul "Pengaruh Strategi Pembelajaran terhadap Kemampuan Kognitif dan Kreativitas dalam Menyelesaikan Soal Matematika (Studi Eksperimen pada Siswa SMP Negeri seKabupaten Bone)”.

Berdasarkan latar belakang di atas, dapat dirumuskan permasalahan sebagai berikut: (1) Apakah terdapat perbedaan Kemampuan Kognitif dan Kreativitas dalam Menyelesaikan Soal Matematika Siswa yang diajar dengan Strategi Pembelajaran Mind Map dan Strategi Pembelajaran Ekspositori? (2) Apakah terdapat perbedaan Kemampuan Kognitif Siswa yang diajar dengan Strategi Pembelajaran Mind Map dan Strategi Pembelajaran Ekspositori?(3) Apakah terdapat perbedaan Kreativitas dalam Menyelesaikan Soal Matematika Siswa yang diajar dengan Strategi Pembelajaran Mind Map dan Strategi Pembelajaran Ekspositori?

Penelitian ini bertujuan untuk menjawab rumusan masalah yang telah dikemukakan diatas, yaitu untuk memperoleh informasi tentang ada tidaknya pengaruh strategi pembelajaran Mind Map terhadap kemampuan kognitif dan kreativitas dalam mengerjakan soal matematika. Dan juga untuk memperoleh informasi jawaban terhadap pertanyaanpertanyaan penelitian, yaitu : (1) Tentang perbedaan kemampuan kognitif dan kreativitas dalam mengerjakan soal antara Strategi Pembelajaran Mind Map dengan Strategi Pembelajaran Ekspositori dalam Pembelajaran Matematika. (2) Tentang perbedaan kemampuan kognitif antara Strategi Pembelajaran Mind Map dengan Strategi Pembelajaran Ekspositori dalam pembelajaran matematika. (3) Tentang perbedaan kreativitas dalam menyelesaikan soal antara Strategi Pembelajaran Mind Map dengan Strategi Pembelajaran Ekspositori dalam pembelajaran matematika.

Manfaat yang diharapkan dari pelaksanaan penelitian ini adalah bagi siswa, sebagai bahan untuk lebih meningkatkan kegiatan pembelajaran. Khususnya pembelajaran matematika diharapkan dapat memberikan informasi tentang pembelajaran inovatif yang mengembangkan kemampuan belajar siswa. Bagi guru, diharapkan hasil penelitian ini dapat memberikan informasi bagi guru tentang suatu teknik di dalam pembelajaran yang mengembangkan kreativitas dan potensi siswa, serta memudahkan siswa menguasai materi pelajaran dan meningkatkan retensi siswa.

Adapun rumusan hipotesis statistik pada penelitian ini sebagai berikut:

$1 . H_{0}:\left[\begin{array}{l}\mu_{A 1 Y 1} \\ \mu_{A 1 Y 2}\end{array}\right]=\left[\begin{array}{l}\mu_{A 2 Y 1} \\ \mu_{A 2 Y 2}\end{array}\right]$

yang berarti semua nilai rata-rata sama besar (tidak berbeda), lawan 
$H_{1}$ : paling sedikit ada satu nilai rata-rata perolehan $\mu_{A Y}(A=1,2 ; y=1,2)$

2. $H_{0}: \mu_{A 1 Y 1}=\mu_{A 2 Y 1}$ lawan $H_{1}: \mu_{A 1 Y 1} \neq \mu_{A 2 Y 1}$

3. $H_{0}: \mu_{A 1 Y 2}=\mu_{A 2 Y 2}$ lawan $H_{1}: \mu_{A 1 Y 2} \neq \mu_{A 2 Y 2}$

Keterangan :

$\mu_{A 1 Y 1}=$ rata-rata kemampuan kognitif matematika siswa yang diajar dengan strategi pembelajaran mind map

$\mu_{A 2 Y 1}=$ rata-rata kemampuan kognitif matematika siswa yang diajar dengan strategi pembelajaran ekspositori

$\mu_{A 1 Y 2}=$ rata - rata kreativitas dalam menyelesaikan soal matematika yang siswa diajar dengan strategi pembelajaran mind map

$\mu_{A 2 Y 2}=$ rata - rata kreativitas dalam menyelesaikan soal matematika siswa yang diajar dengan strategi pembelajaran ekspositori.

\section{A. METODE PENELITIAN}

Penelitian ini adalah jenis penelitian eksperimen dengan menerapkan strategi pembelajaran mind map dan strategi pembelajaran ekspositori, untuk melihat pengaruhnya terhadap kemampuan kognitif dan kreativitas siswa dalam menyelesaikan Soal Matematika. Penelitian eksperimen ini menggunakan model rancangan factorial design sebagai berikut.

Tabel 1. Rancangan Penelitian

\begin{tabular}{l|c|c|c}
\hline \multicolumn{3}{c}{ Strategi Pembelajaran } \\
\hline \multicolumn{2}{c}{ Mind Map ( A1) } & \multicolumn{2}{c}{ Ekspositori (A2) } \\
\hline \multicolumn{2}{c|}{$\mathrm{Y}=(\mathrm{Y} 1, \mathrm{Y} 2)$} & \multicolumn{2}{c}{$\mathrm{Y}=(\mathrm{Y} 1, \mathrm{Y} 2)$} \\
\hline $\mathrm{Y} 1.1$ & $\mathrm{Y} 1.2$ & $\mathrm{Y} 2.1$ & $\mathrm{Y} 2.2$ \\
\hline
\end{tabular}

Keterangan:

$\mathrm{Y}=(\mathrm{Y} 1, \mathrm{Y} 2) \quad=$ Vektor nilai rata-rata

Y1 = Kemampuan Kognitif

Y2 = Kreativitas

AI $\quad=$ Strategi pembelajaran mind map

A2 $=$ Strategi pembelajaran ekspositori

Penelitian ini dilaksnakan pada Bulan Agustus 2018 dan dilaksanakan di dua sekolah yaitu SMP Negeri 1 Watampone dan SMP Negeri 2 Watampone. 
Populasi penelitian adalah seluruh SMP Negeri yang terakreditasi A di SMP Negeri Kabupaten Bone. Adapun sampel penelitian adalah siswa kelas VII.B untuk SMP Negeri 1 Watampone dan Siswa kelas VII.A untuk SMP Negeri 2 Watampone. Sampelnya adalah Kelas VII.B SMP Negeri 1 Watamponesebanyak 25 siswa dan Kelas VII.A SMP Negeri 2 Watampone sebanayak 25 siswa. Variabel dalam penelitian ini adalah stategi pembelajaran dengan menggunakan mind mapdan ekspositorisebagai variabel bebas serta kemampuan kognitif dan kreativitas dalam menyelesaikan soal Matematika sebagai variabel terikat. Teknik pengumpulan data dengan menggunakan instrumen tes hasil belajar berbentuk essay.

Teknik analisis data dengan analisis deskriptif dan analisis inferensial (MANOVA)dengan menggunakan Program SPSS 22.00.

\section{B. HASIL DAN PEMBAHASAN}

Untuk menjawab hipotesis penelitian dengan menggunakan uji $\mathrm{T}$ dan analisis ragam multivariate satu arah (One-Way MANOVA).

1. Pada hipotesis pertama "Terdapat perbedaan kemampuan kognitif dan kreativitas dalam menyelesaikan soal matematika siswa yang diajar dengan strategi pembelajaran mind map dan strategi pembelajaran ekspositori", dengan hipotesis statistik sebagai berikut:

$$
H_{0}:\left[\begin{array}{l}
\mu_{A 1 Y 1} \\
\mu_{A 1 Y 2}
\end{array}\right]=\left[\begin{array}{l}
\mu_{A 2 Y 1} \\
\mu_{A 2 Y 2}
\end{array}\right]
$$

yang berarti semua nilai rata-rata sama besar (tidak berbeda), lawan

$H_{1}$ : paling sedikit ada satu nilai rata-rata perolehan $\mu_{A Y}(A=1,2 ; y=1,2)$ yang berbeda dengan nilai rata-rata perlakuan lainnya.

Berdasarkan hasil analisis data yang dapat dilihat pada lampiran 14, diperoleh nilai probabilitas $=0,000<\alpha=0,05$ (Wilks Lambda), maka dapat disimpulkan bahwa $\mathrm{H}_{0}$ ditolak dan $\mathrm{H}_{1}$ diterima yaitu ada perbedaaan nilai rata-rata kemampuan kognitif dan kreativitas siswa dalam menyelesaikan soal matematika antara siswa yang diajar dengan strategi pembelajaran mind map dengan siswa yang diajar dengan strategi pembelajaran ekspositori. Karena pada hipotesis pertama diputuskan menolak 0 (nol), maka dilanjutkan pengujian untuk hipotesis kedua 
2. Pada hipotesis kedua "Terdapat perbedaan kemampuan kognitif dalam pembelajaran matematika siswa yang diajar dengan strategi pembelajaran mind map dan strategi pembelajaran ekspositori". Dengan hipotesis statistik sebagai berikut

$$
H_{0}: \mu_{A 1 Y 1}=\mu_{A 2 Y 1} \text { lawan } H_{1}: \mu_{A 1 Y 1} \neq \mu_{A 2 Y 1}
$$

Berdasarkan hasil analisis data yang dapat dilihat pada Lampiran 14 sebagaimana Tabel Parameter Estimatesdiperoleh nilai statistik uji-t; $t_{0}=14,957$ dengan $\mathrm{dk}=46 \mathrm{dan}$ nilai $p$-sign $=0,000$. Karena nilai $\quad p$-sign $=0,000<\alpha=0,05$, maka $\mathrm{H}_{0}$ ditolak dan $\mathrm{H}_{1}$ diterima . Dengan demikian dapat disimpulkan bahwa terdapat perbedaan rerata antara kemampuan kognitif yang diajar dengan strategi pembelajaranmind map dan strategi pembelajaran ekspositori.Karena hipotesis kedua menolak 0 (nol)maka dilanjutkan pengujian untuk hipotesis ketiga.

3. Hipotesis ketiga "Terdapat perbedaan kreativitas siswa dalam menyelesaikan soal matematika siswa yang diajar dengan strategi pembelajran mind map dan strategi pembelajaran" dengan hipotesis statistik sebagai berikut :

$$
H_{0}: \mu_{A 1 Y 2}=\mu_{A 2 Y 2} \text { lawan } H_{1}: \mu_{A 1 Y 2} \neq \mu_{A 2 Y 2}
$$

Berdasarkan hasil analisis data yang data dilihat pada lampiran 14, sebagaimana tabel Parameter Estimatesdiperoleh nilai statistik uji-t; $\mathrm{t}_{0}=7,348$ dengandk=46dan nilai $p$ sign $=0,000$. Karena nilai $p$-sign $=0,000<\alpha=0,05$, maka $\mathrm{H}_{0}$ ditolak dan $\mathrm{H}_{1}$ diterima . Dengan demikian dapat disimpulkan bahwa terdapat perbedaan rerata antara kreativitas dalam menyelesaikan soal matematika yang diajar dengan strategi pembelajaranmind map dan strategi pembelajaran ekspositori.

\section{PEMBAHASAN}

Berdasarkan hasil analisis inferensial,dapat dikemukakan bahwa.

a. Terdapat perbedaan kemampuan kognitif dan kreativitas dalam menyelesaikan soal matematika siswa yang diajar dengan strategi pembelajaran mind map dan strategi pembelajaran ekspositori.

Dimana diperoleh nilai probabilitas $=0,000<\alpha=0,05$, maka dapat disimpulkan bahwa menolak 0 (nol) yaitu ada perbedaaan nilai rata-rata kemampuan kognitif dan kreativitas dalam menyelesaikan soal matematika antara siswa yang diajar dengan strategi pembelajaran mind map dengan siswa yang diajar dengan strategi pembelajaran 
ekspositori.Hal ini berarti bahwa strategi pembelajaran mind map memberikan hasil yang signifikan terhadap kemampuan kognitif siswa dan kreativitas dalam menyelesaikan soal matematika. Hal ini didukung dengan teori Buzan (2006) mind map merupakan metode mencatat dalam bentuk pohon, dengan gambar, warna symbol, pola dan asosiasi. Yang dapat mengembangkan kemampuan berpikir matematis atau menggunakan pola pikir matematis.Karena mind map atau pemetaan pikiran merupakan satu bentuk belajar yang efektif untuk memahami kerangka konsep materi pelajaran. Keragaman materi pada berbagai mata pelajaran dikemas dalam disain pikir yang artistik dan kreatif.Lebih menari perhatian. Mind map juga dapat guru latihkan agar siswa belajar tentang yang guru ajarkan. Masalahnya, tanpa strategi ini dapat terjadi siswa mempelajari yang bukan guru sedang ajarkan.Mind map menggunakan kemampuan otak akan pengenalan visual untuk mendapatkan hasil yang sebesarbesarnya. Dengan kombinasi warna, gambar, dan cabang-cabang melengkung.Mind map lebih meransang secara visual dari pada metode pencatatan tradisional, yang cenderung linier satu warna. Bagi siswa, pembelajaran dengan strategi pembelajaran mind map merupakan pendekatan keseluruhan otak yang dapat membuat catatan yang mnyeluruh dalam satu halaman. Dengan menerapkan strategi pembelajaran mind map keterlibatan siswa untuk turut belajar merupakan salah satu indikator keefektifan pembelajaran. Siswa tidak hanya menerima materi dari guru, melainkan siswa juga berusaha menggalui dan mengembangkan sendiri.Kemampuan kognitif tidak hanya menghasilkan peningkatan pengetahuan tetapi juga meningkatkan kreativitas berpikir. Oleh karena itu penerapan pembelajaran dengan strategi pembelajaran mind map dapat melatih siswa belajar kreatif, meningkatkan kreativitas berpikir siswa. Sehingga strategi pembelajaran mind map dapat mempengaruhi kemampuan kognitif siswa. Sejalan dengan pendapat Iwan Sugiarto (2004: 75) mengemukakan "pemetaan pikiran (mind mapping) adalah teknik meringkas bahan yang perlu dipelajari, dan memproyeksikan masalah yang dihadapi ke dalam bentuk peta atau teknik grafik sehingga lebih mudah memahaminya”. Kegiatan ini sebagai upaya yang dapat mengoptimalkan fungsi otak kiri dan kanan, yang kemudian dalam aplikasinya sangat membantu untuk memahami masalah dengan cepat karena telah terpetakan.

Jika pengajar mampu mengajarkan keterampilan berpikir, maka pembelajar akan memiliki kemampuan kognitif dan kreativitas dalam menyelesaikan soal yang 
sangat dibutuhkan dalam membangun kepribadian yang mandiri yang mampu mengelola sendiri proses belajarnya (self regulated learning) dan mengkontruksi sendiri pengetahuannya. Pembelajar yang dimaksud adalah siswa. Jika siswa mempunyai kemampuan kognitif dan kreativitas berpikir yang tinggi maka akan memperoleh hasil belajar yang tinggi pula.

b. Terdapat perbedaan kemampuan kognitif siswa yang diajar dengan strategi pembelajaran mind map dan strategi pembelajaran ekspositori.

Hasil analisis juga menunjukkan bahwa rata-rata kemampuan kognitif siswa yang diajar dengan strategi pembelajaran mind map berbeda secara signifikan dengan siswa yang diajar dengan strategi pembelajaran ekspositori dengan nilai statistik $\mathrm{t}=$ 14,957 dengan $\mathrm{dk}=46 \mathrm{dan}$ nilai $p$-sign $=0,000$. Karena nilai $p$-sign $=0,000<\alpha=0,05$, maka diputuskan menolak 0 (nol). Dengan demikian, dapat disimpulkan bahwa terdapat perbedaan antara kemampuan kognitif yang diajar dengan strategi pembelajaran mind map dan strategi pembelajaran ekspositori. Hal ini berarti bahwa strategi pembelajaran mind map memberikan hasil yang signifikan terhadap kemampuan kognitif. Dengan menerapkan strategi pembelajaran mind map keterlibatan siswa untuk belajar merupakan salah satu indikator keefektifan belajar. Depdiknas (2007:3) Pengembangan kemampuan kognitif bertujuan agar anak mampu megolah perolehan belajarnya, menemukan bermacam-macam alternative pemecahan masalah, pengembangan kemampuan logika matematika, pengetahuan ruang dan waktu, kemampuan memilah dan mengelompokkan, dan persiapan pengembangan kemampuan berpikir teliti. Sedangkan keterlibatan siswa yang diajar dengan strategi pembelajaran ekspositori, dalam proses belajar mengajar kurang Nampak. Peran guru sangat dominan karena harus menjelaskan materi dengan tuntas.Hal ini menyebabkan hanya beberapa siswa yang terlibat aktif dalam pembelajaran.Saat guru memberikan kesempatan untuk mengajukan pertanyaan, hanya beberapa siswa yang terlihat antusias.Sebagian besar siswa hanya duduk mendengar guru berceramah dan menyalin penjelasan yang diberikan oleh guru.Demikian pula saat guru memberikan latihan soal-soal, hanya beberapa siswa yang terlihat aktif mengerjakan soal-soal tersebut.Siswa memiliki kecenderungan menunggu jawaban dari guru. Oleh karena itu, pembelajaran dengan strategi pembelajaran mind map sangat membantu siswa dalam memudahkan memahami pelajaran dengan cepat karena potensi siswa (pemikiran/ jalan berpikir) 
dilibatkan dalam pembelajaran, sehingga strategi pembelajaran mind map dapat mempengaruhi kemampuan kognitif dan kreativitas siswa.

c. Terdapat perbedaan kreativitas dalam menyelesaikan soal matematika siswa yang diajar dengan strategi pembelajaran mind map dan strategi pembelajaran ekspositori.

Hasil analisis juga menunjukkan bahwa rata-rata kreativitas dalam menyelesaikan soal matematika siswa yang diajar dengan strategi pembelajaran mind map berbeda secara signifikan dengan siswa yang diajar dengan strategi pmebelajaran ekspositori dengan nilai statistik $\mathrm{t}=7,348$ dengan $\mathrm{dk}=46 \mathrm{dan}$ nilai $p$-sign $=0,000$. Karena nilai $\quad p$-sign $=0,000<\alpha=0,05$, maka diputuskan menolak 0 ( nol ). Dengan demikian dapat disimpulkan bahwa terdapat perbedaan antara kreativitas dalam menyelesaikan soal matematika siswa yang diajar dengan strategi pembelajaran mind map dan strategi pembelajaran ekspositori.

Aspek kreativitas dalam menyelesaikan soal matematika yang digunakan dalam penelitian ini yaitu (a) kelancaran (fluency), (b) keluwesan (flexibility), (c) keaslian (originality). Berikut ini beberapa hasil pengamatan peneliti terhadap pekerjaan siswa dalam tes.

(a) Kelancaran

Indikator dari aspek kelancaran adalah siswa meghasilkan banyak ide atau gagasan dari informasi yang diberikan. Pada kelas eksperimen 1, siswa pada strategi pembelajaran mind map soal yang diselesaikan dengan kecepatan menjawab yang cepat dan benar serta jawaban sesuai dengan langkah-langkah penyelesaian soal yang sebenarnya dimana aspek kelancaran (fluency) 68,65\%, pada strategi pembelajaran ekspositori atau pada kelas eksperimen 2 yaitu kelas yang dikenai perlakuan strategi pembelajaran ekspositoriaspek kelancaran (fluency) $57,10 \%$.

(b) Keluwesan

Indikator dari keluwesan adalah menggunakan strategi-strategi yang beragam (keragaman ide) pada jawaban yang dibuatnya. Pada kelas eksperimen 1 atau siswa yang diajar dengan strategi pembelajaran mind map mulai memberikan variasi pada jawaban, aspek keluwesan (flexibility) 53,65\%. Sedang pada kelas 
eksperimen 2 atau siswa yang diajar dengan strategi pembelajaran ekspositori aspek keluwesan (flexibility) 52,71\%.

(c) Keaslian

Indikator aspek keaslian adala siswa dapat memunculkan ide-ide yang unik dalam menyusun jawaban dengan tepat. Pada kelas eksperimen atau siswa yang diajar dengan strategi pembelajaran mind map dan siswa yang diajar dengan strategi pembelajaran ekspositori siswa mulai mampu memunculkan jawaban dengan modifikasi jawaban yang pernah di temui pada kelas eksperimen 1 aspek keaslian (originality) 51,98\% sedang pada kelas eksperimen 2 siswa yang diajar dengan strategi pembelajaran ekspositori $51,56 \%$. Dalam kreativitas proses memodifikasi adalah hal penting karena dari sisni muncul produk-produk baru. Yang dimaksud dengan produk baru bukan produk yang sama sekali baru dan belum pernah ada yang menyamai tetapi produk modifikasi juga bisa dikatakan produk baru.

\section{KESIMPULAN DAN SARAN}

Berdasarkan hasil penelitian dan pembelajaran, maka dapat disimpulkan sebagai berikut :

1. Terdapat perbedaan kemampuan kognitif dan kreativitas dalam menyelesaikan soal matematika siswa yang diajar dengan strategi pembelajaran mind map dan strategi pembelajaran ekspositori.

2. Terdapat perbedaan kemampuan kognitif siswa yang diajar dengan strategi pembelajaran mind map dan strategi pembelajaran ekspositori. Dimana kemampuan kognitif siswa yang diajar dengan strategi pembelajaran mind map pada kelas eksperimen 1 memiliki tingkat kemampuan kognitif dalam kategori tinggi 41,7 \% dengan skor rata-rata 73,9583 dan standar deviasi 1,87615. Kemampuan kognitif siswa yang diajar dengan strategi pembelajaran Ekspositori pada kelas eksperimen 2 memiliki tingkat kemampuan kognitif dalam kategori sedang dengan skor rata-rata 64,8750 dan standar deviasi 2,30901 .

3. Terdapat perbedaan kreativitas dalam menyelesaikan soal matematika siswa yang diajar dengan strategi pembelajaran mind map dan strategi pembelajaran 
ekspositori. Dimana kreativitas dalam menyelesaikan soal matematika siswa yang diajar dengan strategi pembelajaran mind map pada kelas eksperimen 1 memiliki tingkat kreativitas dalam menyelesaikan soal matematika dalam kategori sedang pada aspek kelancaran (fluency) 68,65\%, keluwesan (flexibility) 53,65\%, dan keaslian (originality) 51,98 \% dengan skor rata-rata 69,7083 dan standar deviasi 2,62892. Kreativitas dalam menyelesaikan soal matematika siswa yang diajar dengan strategi pembelajaran ekspositori pada kelas eksperimen 2 memiliki tingkat kreativitas dalam menyelesaikan soal matematika dalam kategori sedang pada aspek kelancaran (fluency) 57,10\%, keluwesan (flexibility) 52,71\%, dan keaslian (originality) 51,56 \% dengan skor rata-rata 64,5417 dan standar deviasi 2,22592.

Berdasakan hasil penelitian ini, penulis menyarankan bahwa bagi yang melakukan penilitian selanjutnya harus berhubungan dengan strategi pengajaran yang diteliti di atas agar kiranya lebih memperhatikan hal-hal yang berhubungan dengan pemahaman konsep matematika terlebih kepada kemampuan kognitif dan kreativitas siswa SMP.

\section{DAFTAR RUJUKAN}

Anurrrahman. 2009. Belajar dan Pembelajaran. Bandung: CV. Alfabeta.

Buzan, T. 2006. Buku Pintar Mind Map.Terjemahan oleh Susi Purwoko.Jakarta : Gramedia. Pustaka Utama.

Bobby De Porter \& Mike Hernacki. 2004. Quantum Learning(Membiasakan Belajar Nyaman dan Menyenangkan).Terjemahan oleh Alwiyah Abdurrahman.Bandung : Karya

Depdiknas. 2007. Pedoman Pengembangan Fisik/Motorik. Jakarta : Departemen Pendidikan Nasional

Dryden, Vos, J. 2001. Revolusi Cara Berpikir, Keajaiban Pikiran Sekolah Masa Depan. Penerjemah (Word++Translation Service).Jakarta : Kaifa

Femi, Olivia. 2002. Gembira Belajar dengan Mind Mapping.Jakarta : Elex Media Kompetindo.

Harsanto, Ratno. (2005). Melatih anak berpikir analisis, kritis, dan kreatif.Jakarta: Gramedia. 
Ima, Hernawati 2009.Teori, Konsep, dan Aplikasi dengan SPSS. Badan Penerbit Universitas Diponegoro, Semarang.

Mann, E. 2005.Mathematical Creativity and School Mathematics: Indicators of Mathematical Creativity in Middle School Students.Disertasi Universityof Connecticut.(15November 2007)

Muhajirin. 2011. Pengaruh Mind Mapping dengan Medi Gambar terhadap Hasil Belajar Biologi Siswa kelas X SMA Negeri 2 Ajangale. Skripsi: STKIP Puangrimaggalatung Sengkang

Muhammad, Ashori. 2007. Psikologi Pembelajaran.Bandung : Wacana Prima.

Nuraini. 2011. Pengaruh Strategi Mind Map terhadap Peningkatan Hasil Belajar Siswa Kelas VIII SMP Negeri 26 Makassar. Skripsi : UIN Alauddin Makassar.

Nurharini,Dewi. Matematika Konsep dan Aplikasinya Kelas VII SMP dan MTs. Pusat Perbukuan Departemen Pendidikan Nasional

Nurhinsyani. 2010. Departemen Pendidikan Nasional dan Kebudayaan.

Ngalim Purwanto, M. 2012. Prinsip-Prinsip dan Teknik Evaluasi Pendidikan.Bandung : PT. Remaja Rosdakarya.

Park, H. 2004. The Effects of Divergent Production Activities With Math Inquiry and Think Aloud of Students With Math Difficulty. Disertasi[online]: http://txspace.tamu.edu/bitstream/handle/1969.1/2228/etd-tamu-2004.[15 November]

Roestiyah, N.K. 2008. Strategi Belajar Mengajar. Jakarta : Rineka Cipta

Ruslan. 2009. Validasi Isi. Pabbiritta (ISSN : 1829 - 6334). Makassar : LPMP Sulawesi Selatan.

Sagala, Syaiful. 2010. Konsep dan makna pembelajaran untuk membantu memecahkan problematika belajar dan mengajar, Bandung: CV. Alfabeta.

Sudaryono. 2013. Pengembangan Instrumen Penelitian Pendidikan. Yogyakarta : Graha Ilmu.

Sudjana.Nana .2008 Penilaian Hasil Proses Belajar Mengajar, Bandung: Remaja Rosda Karya.

Sudiarta, P. 2006. Pengembangan model pembelajaran berorientasi pemecahan masalah openendedberbantuan LKM untuk meningkatkan pemahaman konsep dan hasil belajarmahasiswa matakuliah pengantar dasar Matematika.Jurnal Pendidikan dan PengajaranUNDIKSHA 39 Nomor 2, April 2006. Singaraja: UNDIKSHA. 
Sugiarto, Iwan. (2004). Mengoptimalkan daya kerja otak dengan berpikir holistik \& kreatif.Jakarta: Gramedia Utama

Suherman, Erman. dkk. 2003. Strategi Pembelajaran Matematika Kontemporer. JICA:.Bandung.

Sukmadinata,2011.Landasan Psikologis Proses Pendidikan. Bandung: Remaja.

Susetyo, Budi. 2011. Menyusun Tes Hasil Belajar Dengan Teori Ujian Klasik Dan Teori Respons butir. Bandung: CV Cakra.

Trianto, 2009.Mendesain model pembelajaran inovatif-progresif: konsep, landasan, dan implementasinya pada kurikulum tingkat satuan pendidikan (KTSP), Jakarta: Kencana Prenada Media Group.

Uno, Hamzah B, 2009. Model Pembelajaran Menciptakan Proses Belajar Mengejar yang Kreatif dan Efektif .Jakarta : Bumi Aksara

Yovan. 2008. Memori dan Pembelajaran Efektif. Bandung : Yrama Widya 